\title{
Significance of Photosynthetic Characters in the Evolution of Asian Gnetum (Gnetales)
}

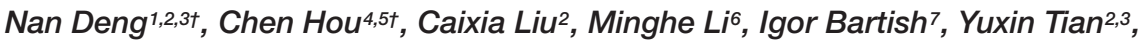 \\ Wei Chen ${ }^{1}$, Changjian Du ${ }^{1}$, Zeping Jiang ${ }^{1,8 *}$ and Shengqing Shit ${ }^{1 *}$
}

${ }^{1}$ State Key Laboratory of Tree Genetics and Breeding, Key Laboratory of Tree Breeding and Cultivation of State Forestry Administration, Research Institute of Forestry, Chinese Academy of Forestry, Beijing, China, ${ }^{2}$ Hunan Academy of Forestry, Changsha, China, ${ }^{3}$ Hunan Cili Forest Ecosystem State Research Station, Cili, China, ${ }^{4}$ School of Life Sciences, Sun Yat-sen University, Guangzhou, China, ${ }^{5}$ Department of Ecology, Environment and Plant Sciences, Stockholm University, Stockholm, Sweden, ${ }^{6}$ College of Landscape Architecture, Fujian Agriculture and Forestry University, Fuzhou, China, ${ }^{7}$ Department of Genetic Ecology, Institute of Botany, Academy of Sciences of Czech Republic, Praha, Czechia, ${ }^{8}$ Institute of Forest and Ecology Protection, Chinese Academy of Forestry, Beijing, China

\section{OPEN ACCESS}

Edited by:

Badri Padhukasahasram, Illumina, United States

Reviewed by: Rosa Amelia Scherson,

Universidad de Chile, Chile

Alejandra Vázquez-Lobo, Universidad Autónoma del Estado de Morelos, Mexico

*Correspondence:

Zeping Jiang

jiangzp@caf.ac.cn

Shengqing Shi

shi.shengqing@caf.ac.cn

${ }^{+}$Co-first authors

Specialty section:

This article was submitted to Evolutionary and Population Genetics, a section of the journal

Frontiers in Plant Science

Received: 05 September 2018

Accepted: 10 January 2019

Published: 05 February 2019

Citation:

Deng N, Hou C, LiU C, Li M. Bartish I, Tian Y, Chen W, Du C, Jiang $Z$ and Shi S (2019) Significance of Photosynthetic Characters

in the Evolution of Asian Gnetum (Gnetales). Front. Plant Sci. 10:39. doi: 10.3389/fpls.2019.00039
Gnetum is a genus in the Gnetales that has a unique but ambiguous placement within seed plant phylogeny. Previous studies have shown that Gnetum has lower values of photosynthetic characters than those of other seed plants, but few Gnetum species have been studied, and those that have been studied are restricted to narrow taxonomic and geographic ranges. In addition, the mechanism underlying the lower values of photosynthetic characters in Gnetum remains poorly understood. Here, we investigated the photosynthetic characters of a Chinese lianoid species, i.e., Gnetum parvifolium, and co-occurring woody angiosperms growing in the wild, as well as seedlings of five Chinese Gnetum species cultivated in a greenhouse. The five Gnetum species had considerably lower values for photosynthesis parameters (net photosynthetic rate, transpiration rate, intercellular $\mathrm{CO}_{2}$ concentration, and stomatal conductance) than those of other seed plant representatives. Interrelated analyses revealed that the low photosynthetic capacity may be an intrinsic property of Gnetum, and may be associated with its evolutionary history. Comparison of the chloroplast genomes (cpDNAs) of Gnetum with those of other seed plant representatives revealed that 17 coding genes are absent from the cpDNAs of all species of Gnetum. This lack of multiple functional genes from the cpDNAs probably leads to the low photosynthetic rates of Gnetum. Our results provide a new perspective on the evolutionary history of the Gnetales, and on the ecophysiological and genomic attributes of tropical biomes in general. These results could also be useful for the breeding and cultivation of Gnetum.

Keywords: photosynthesis, chloroplast genomes, phylogeny, seed plants evolution, gymnosperms

\section{INTRODUCTION}

The Gnetales comprises three genera i.e., Ephedra L., Welwitschia Hook. f., and Gnetum L, and forms a monophyletic group, as indicated by morphological and molecular data (Price, 1996; Doyle, 1998; Rydin and Korall, 2009). The Gnetales are morphologically different from other gymnosperms and their phylogenetic placement within seed plants is unclear (Doyle and Donoghue, 1986; Friedman, 1998; 
Burleigh and Mathews, 2004). Previous paleobiological, palynological, morphogenetic, and anatomical studies have suggested that there is a close relationship between the Gnetales and angiosperms, i.e., the "anthophyte" hypothesis (Crane, 1985; Doyle and Donoghue, 1986, 1992). However, molecular phylogenies generated in last decade have placed the Gnetales as a sister group to the Pinaceae (the "gnepine" hypothesis), conifers (the "gnefers" hypothesis, Soltis et al., 2002; Ickert Bond and Wojciechowski, 2004; Wu et al., 2007; Zhong et al., 2010; Gong et al., 2016; Ickert Bond and Renner, 2016; Mao et al., 2017; Ran et al., 2018; Wan et al., 2018), or other seed plants (Chen et al., 2016). The ambiguous placement of the Gnetales within seed plant phylogenies is ascribed to the lack of homologous features among different plant groups.

Gnetum comprises around 40 species. Most Gnetum species are woody climbers and a few species are shrubs and trees (Markgraf, 1930, 1951, 1965; Hou et al., 2015). The genus has a broad distribution in lowland mixed and dense areas of pantropical forests. Leaves of Gnetum are rich in bioactive compounds, e.g., flavonoids and stilbenes, which have remarkable medical effects (Deng et al., 2016, 2017). Phylogenetic studies based on molecular data have shown that South American Gnetum, African Gnetum, and Asian Gnetum constitute the three major clades of the genus (Won and Renner, 2006; Hou et al., 2016). Within Asian Gnetum, two arborescent species Gnetum gnemon L. and G. costatum K. Schum comprise a sister clade to other (lianoid) Chinese and Indo-Malayan species (Hou et al., 2015, 2016). The phylogenetic relationships and delimitations of Chinese lianoid Gnetum have been resolved in a recent study based on morphological and molecular data (Hou et al., 2016).

Gnetum species are characterized by such traits as decussate leaves, pinnate leaf veins, and the presence of vessels in stems, all of which resemble characters of angiosperms (Markgraf, 1930). However, two previous studies found that the photosynthetic and transpiration capacities of Gnetum are considerably lower than those of other seed plants. For example, the photosynthetic capacities of four Gnetum species, i.e., G. costatum, G. gnemon, and Gnetum latifolium Blume, and one unidentified lianoid species were found to be consistently lower than those of co-occurring angiosperms in tropical rainforest in Papua New Guinea (Feild and Balun, 2008). The results showed that all the studied species of Gnetum had lower photosynthetic rates in terms of stomatal conductance and transportation of stem water (Feild and Balun, 2008). The other case was the low values of photosynthetic characters detected in seedlings of Gnetum leyboldii Tul. under greenhouse conditions (Celis and Avalos, 2013). The results of those two studies suggested that the presence of xylem vessels, broad netveined leaves, and lianoid habitats do not necessarily indicate highly opportunistic and light-demanding ecophysiological capacities in Gnetum (Feild and Balun, 2008; Celis and Avalos, 2013).

Nevertheless, it would be premature to draw a robust conclusion that low photosynthetic capacity is a typical feature of Gnetum, since relatively few species have been studied in detail. To the best of our knowledge, the photosynthetic characters of Chinese lianoid Gnetum species have not been analyzed yet. Besides, the intrinsic mechanisms underlying low values of photosynthetic characters of Gnetum are poorly understood. In the present study, the first aim was to compare several photosynthetic characters between Chinese lianoid Gnetum and their co-occurring angiosperms, conifers, and Ginkgo in the wild, as well as under different experimental conditions. The second aim was to compare changes in photosynthetic characters through time among Chinese lianoid species. The last aim was to use photosynthetic character data and sequences of cpDNAs to determine patterns of photosynthetic evolution in the context of seed plant phylogeny. The overall aim of this study was to better understand the role of photosynthetic function in the evolution of the Gnetales using integrated experimental plant physiological, genomic, phylogenetic, systematic, and ecological analyses. The obtained knowledge could be beneficial for the breeding and cultivation of Gnetum.

\section{MATERIALS AND METHODS}

\section{Study Sites and Samples}

Field experiments were conducted at Fuzhou Forest Park (E

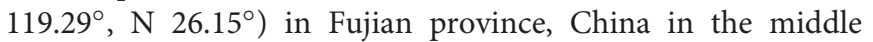
of September 2016. The habitats of Chinese lianoid Gnetum are in the lowland area in mixed and dense subtropical forests. An open site with natural light was selected in a forest-edge zone in the park, where Gnetum parvifolium (Warb.) W. C. Cheng is distributed and grows well alongside several other plants representing some of the main lineages of land plants. Photosynthetic parameters in three individuals of G. parvifolium were measured using the LI-6400 portable photosynthesis system (LI-COR Inc. Lincoln, NE, United States). Photosynthetic parameters were also measured for three selected co-occurring plants; Lonicera japonica Thunb., Styrax confusus Hemsl., and Pteris vittata L. (Table 1). These plants were selected on the basis of the following criteria: (1) they were representatives of main lineages of land plants, i.e., angiosperms and ferns (but not gymnosperms, which grew at heights out of reach at the site); (2) they were representatives of liana with broad leaves like those of Gnetum; (3) cpDNA sequences were available for them or for other species in their genus.

At the field site $(8 \times 2 \mathrm{~m})$, three individuals of $G$. parvifolium and co-occurring species were randomly selected, but all were at least $2 \mathrm{~m}$ away from other individuals of the same species. The photosynthetic characters of selected plants were measured at 8:30-10:00 a.m., and measurements were repeated three times on 3 consecutive days, with the ambient temperature around $30^{\circ} \mathrm{C}$, photosynthetic photon flux density (PPFD) between 850 and $950 \mu \mathrm{mol} \mathrm{m} \mathrm{m}^{-2} \mathrm{~s}^{-1}$ and carbon dioxide $\left(\mathrm{CO}_{2}\right)$ level around $400 \mu \mathrm{mol} \mathrm{mol}{ }^{-1}$. Because Gnetum are evergreen trees, we measured photosynthetic characters of old leaves (at the base) and young leaves (usually at the top) in the current-year branches of G. parvifolium. For the other three plant species, we 


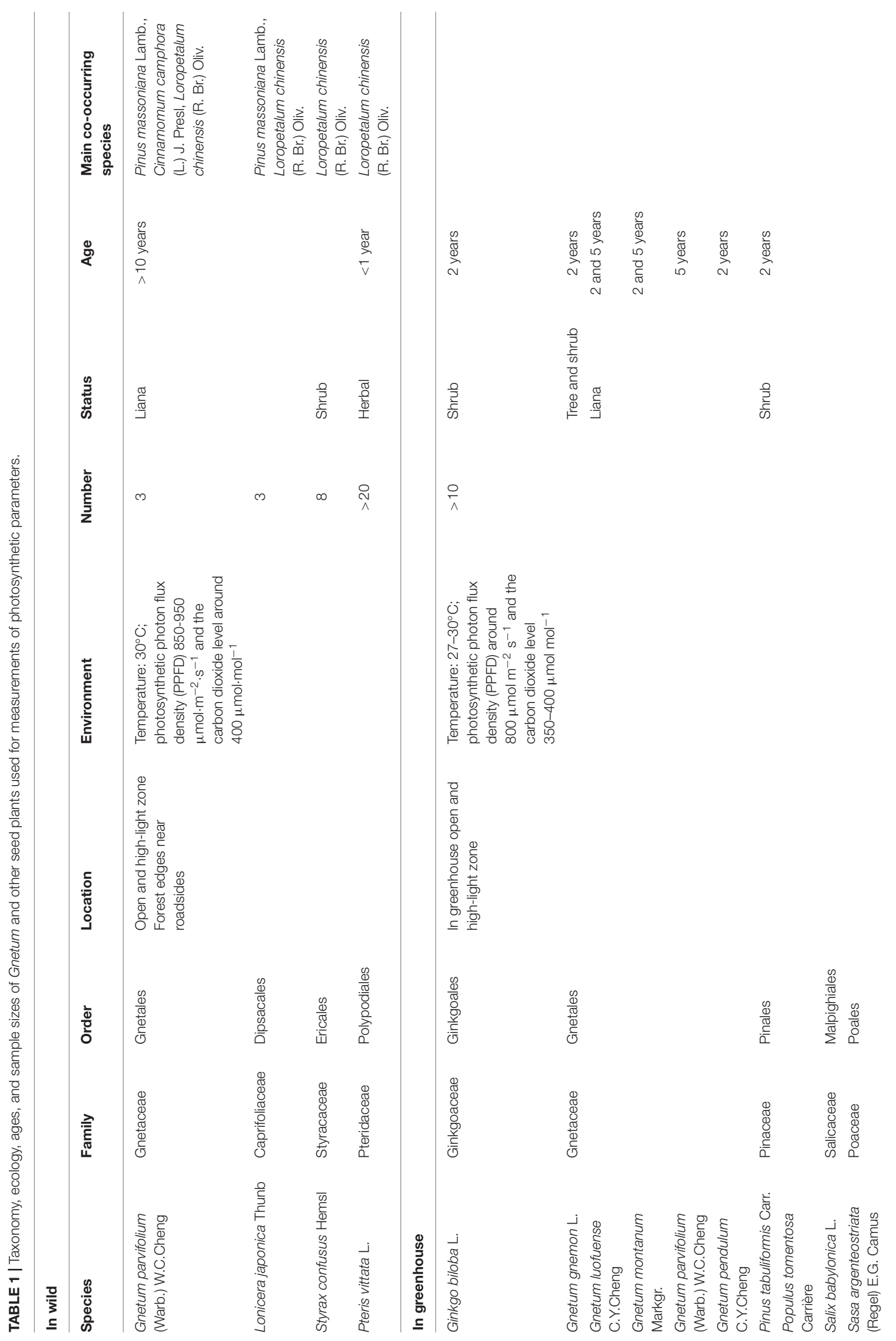


measured photosynthetic parameters of fully opened leaves (functional leaves) at similar internodes from the shoot tip. The final values of photosynthetic parameters were the average of values measured over the 3 days of observations.

We also conducted experiments at 8:30-10:00 a.m. in the greenhouse of the Chinese Academy of Forestry, Beijing, China from June to September 2016. The conditions in the indoor environment were adjusted to levels similar to those at the field site: i.e., temperature around $27^{\circ} \mathrm{C}, \mathrm{PPFD}$ around $800 \mu \mathrm{mol} \mathrm{m}{ }^{-2} \mathrm{~s}^{-1}$; and $\mathrm{CO}_{2}$ around $350-400 \mu \mathrm{mol} \mathrm{mol}{ }^{-1}$. We measured photosynthetic characters of 2-year-old seedlings of one arborescent species (i.e., Gnetum gnemon), and four lianoid species (i.e., Gnetum pendulum C. Y. Cheng, Gnetum montanum Markgr., G. parvifolium, and Gnetum luofuense C. Y. Cheng). We compared photosynthetic characters between 2-year-old and 5-year-old seedlings of G. montanum and G. luofuense to control for possible ontogenetic shifts in these characters. We also measured photosynthetic characters in four 2-year-old seedlings of Ginkgo biloba L., Pinus tabuliformis Carr., Populus $\times$ tomentosa Carrière, Salix babylonica L., and Sasa argenteostriata (Regel) E.G. Camus. The photosynthetic characters of $P$. tabuliformis were measured in a needle chamber. These plants were selected on the basis of the following criteria: (1) they were representatives of main lineages of seed plants, i.e., angiosperms and gymnosperms; and (2) cpDNA sequences were available for them or for a member of their genus. Table 1 summarizes details of the taxonomy, ecology, ages, and sample sizes of all plants used in this study. The photosynthetic characters of Gnetum and other seed plant representatives were measured from June to September, which was the fruiting season of Gnetum. During this time, the photosynthetic characters were most likely to reach their peaks and reflect the photosynthetic capacity. We measured the photosynthetic characters of four individuals of each species of Gnetum and obtained the mean value for each month. Identical measurements of photosynthetic characters were performed in four individuals each of G. biloba, P. tabuliformis, P. tomentosa, S. babylonica, and S. argenteostriata.

\section{Measurement of Photosynthetic Characters}

Five photosynthetic characters were measured using the LI6400 Portable Photosynthesis System: net photosynthetic rate (Pn) (reflecting the accumulation of photosynthetic products in plants); transpiration rate ( $\mathrm{Tr}$ ) (transport resistance of $\mathrm{CO}_{2}$ and water); intercellular $\mathrm{CO}_{2}$ concentration (Ci) (level of $\mathrm{CO}_{2}$ available for photosynthesis); stomatal conductance (Gs) (stomatal opening in proportion to transpiration); and leaf water deficit ( $\mathrm{Vpdl}$ ) (an index of transpiration). Water use efficiency (WUE) was obtained by dividing Pn by $\mathrm{Tr}$. We measured relative chlorophyll content (Rc), indicative of percentage chloroplast content, using a SPAD502 Plus portable chlorophyll meter (Konica Minolta, Osaka, Japan).
Light- $/ \mathrm{CO}_{2}$-response curves reflect the responses of photosynthetic characters to light intensity (or $\mathrm{CO}_{2}$ concentration). These curves show the photosynthetic efficiency of plants across a photon flux gradient under different concentrations of light $/ \mathrm{CO}_{2}$. In the greenhouse, we produced light $/ \mathrm{CO}_{2}$ response curves for 2-year-old seedlings of the five Gnetum species i.e., G. gnemon, G. luofuense, G. montanum, G. pendulum, and G. parvifolium using the LI-6400 Portable Photosynthesis System (Li-Cor). The light-response curves were generated with a $\mathrm{CO}_{2}$ concentration of $400 \mu \mathrm{mol} \mathrm{mol}^{-1}$ in the greenhouse. For the light response curves, we adjusted the light intensity to a range of levels: 2000, 1800, 1500, 1200, $1000,800,600,400,200,150,100,50$, and $0 \mu \mathrm{mol} \mathrm{m} \mathrm{m}^{-2} \mathrm{~s}^{-1}$, as applied in an earlier study (Palliotti and Cartechini, 2015). Polynomial quadratic equations were calculated (Farquhar et al., 2001) with the best fit to the light-response data for light compensation point (LCP), light saturation point (LSP), maximum photosynthesis rate of light-response (AmaxL), dark respiration rate of light-response (RdL), and apparent quantum yield (AQY). The LCP is the light intensity when the synthesis and consumption of organic materials are equal. The LSP is the minimum light intensity when Pn values reach the maximum. The $\mathrm{RdL}$ is the Pn value when the light intensity is 0 , and indicates the consumption of organic materials without photosynthesis. The AQY is the initial slope when light intensity ranges from 0 to $200 \mu \mathrm{mol} \mathrm{m} \mathrm{m}^{-2} \mathrm{~s}^{-1}$, and reflects the utilization efficiency of plants under weak light (Farquhar et al., 2001).

For the $\mathrm{CO}_{2}$-response curves, we set the light intensity at $1000 \mu \mathrm{mol} \mathrm{m} \mathrm{m}^{-2} \mathrm{~s}^{-1}$ in the greenhouse. We established a gradient of $\mathrm{CO}_{2}$ concentrations: 400, 200, 100, 0, 50, 100, 150, 200, 300, 400, 600,800, 1200, 1500, and $2000 \mu \mathrm{mol} \mathrm{mol}^{-1}$, as described by Yin et al. (2016). We calculated polynomial quadratic equations with the best fit to the light-response data for $\mathrm{CO}_{2}$ compensation point (CCP), $\mathrm{CO}_{2}$ saturation point (CSP), maximum photosynthesis rate of $\mathrm{CO}_{2}$-response (AmaxC), carboxylation efficiency (CE), and dark respiration rate of $\mathrm{CO}_{2}$-response ( $\left.\mathrm{RdC}\right)$. A cubic polynomial was used to fit the curves of the five species of Gnetum in both the light-response and $\mathrm{CO}_{2}$-response curves. The meanings of the photosynthetic characters in the $\mathrm{CO}_{2}$ response curves are identical to those of the light response curves described above.

\section{Analyses of Detected Photosynthetic Characters}

We performed principal component analyses (PCA) and cluster analyses of the five photosynthetic characters among the five Gnetum species and the other seed plant representatives. These analyses allowed us to explore the relationships among these species on the basis of variations in their photosynthetic characters. Data for the five photosynthetic characters, i.e., $\mathrm{Pn}, \mathrm{Tr}, \mathrm{Ci}, \mathrm{Gs}$, and $\mathrm{Vpdl}$, were obtained for all compared species (see above) and standardized prior to analyses. In the PCA analyses, the Kaiser-Guttman criterion was applied for eigenvalue selection (Guttman, 1954; Kaiser, 2016). Six clustering methods, i.e., complete linkage agglomerative 
clustering, single linkage agglomerative clustering, unweighted pair-group method using arithmetic averages (UPGMA), unweighted pair-group method using centroids (UPGMC), weighted pair-group method using centroids (WUPGMA), and Ward's minimum variance clustering, were applied using the same photosynthetic character data as used in the PCA. The application of six cluster methods was an exploratory analysis rather than a statistical test, and allowed us to compare the results of cluster analyses using different algorithms. We calculated the cophenetic correlation coefficient and statistic support for each clustering method using the vegan package implemented in $\mathrm{R}$ platform version 3.4.4 ( $\mathrm{R}$ core team, $\left.2016^{1}\right)$.

\section{Comparison of Chloroplast Genomes of Selected or Related Plants}

The cpDNAs of the 15 plants used in our photosynthetic analyses or belonging to the same genus were downloaded from Genbank ${ }^{2}$. The accession numbers are shown in Table 2. The plants in these analyses were members of the Gnetales, Ginkgo, Pinus, five species of angiosperms, and Pteridium was the outgroup. We used the data matrix of seed plants (Ruhfel et al., 2014) supplemented by the cpDNAs of Chinese lianoid Gnetum (Hou et al., 2016). For each cpDNA, 78 conservative coding genes (listed in Supplementary Table S1) were chosen and aligned using MAFFT version 7.017 (Katoh et al., 2017) and visualized using mVISTA software (Mayor et al., 2000). Maximum likelihood trees were constructed based on concatenation of coding genes using the substitution model GTR+GAMMA implemented in RAxML version 7.2.8 (Stamatakis, 2006). In these analyses, we did not aim to re-evaluate the phylogenetic relationships among the Gnetales and other groups of seed plants. Instead, we reconstructed the phylogeny of selected seed plants as the evolutionary

${ }^{1}$ https://www.r-project.org/

${ }^{2}$ www.ncbi.org context for analyses of photosynthetic characters in this clade.

\section{RESULTS}

\section{Photosynthetic Characters of Gnetum in the Wild}

Our results revealed that the mean $\mathrm{Pn}$ in G. parvifolium was $1.3 \pm 0.33 \mu \mathrm{mol} \mathrm{m} \mathrm{m}^{-2} \mathrm{~s}^{-1} \mathrm{CO}_{2}$, significantly lower than that in $S$. confusus $\left(4.86 \pm 0.08 \mu \mathrm{mol} \mathrm{m} \mathrm{m}^{-2} \mathrm{~s}^{-1}\right)$, the lowest value detected among the four co-occurring species in the wild (Table 3). Similarly, the lowest values of Gs, Ci, and Tr were detected in G. parvifolium. However, the Vpdl and Rc values were significantly higher in G. parvifolium than in three co-occurring species. These results confirmed that Gnetum has a low photosynthetic capacity. To explore this in more detail, we conducted subsequent investigations of photosynthetic characters among five Chinese lianoid species under the same conditions in a greenhouse.

\section{Light-Response Curves of Gnetum}

As shown in the light-response curves, the Pn values plateaued at around $800 \mu \mathrm{mol} \mathrm{m} \mathrm{m}^{-2} \mathrm{~s}^{-1}$ among the four lianoid species, and slightly declined when the concentration of $\mathrm{CO}_{2}$ increased from 1.41 to $2.75 \mu \mathrm{mol} \mathrm{m} \mathrm{m}^{-2} \mathrm{~s}^{-1}$ (Figure 1A). In contrast, the Pn values of the arborescent species G. gnemon steadily increased when exposed to dense light (about $800 \mu \mathrm{mol} \mathrm{m} \mathrm{m}^{-2} \mathrm{~s}^{-1}$ ), but the values were considerably lower than most of those of other plants in the studied light intensity range (Figure 1A). The fitting degree $\left(\mathrm{R}^{2}\right)$ ranged from 0.81 to 0.92 among the five species of Gnetum, indicating a good fit by cubic polynomial equations.

The values of Gs, Tr, and WUE were lower in G. gnemon than in the four lianoid species across most of the photosynthetic photon flux density range (Figures 1B-E). The four lianoid species and G. gnemon were similarly compared in terms of LCP,

TABLE 2 | Taxonomy of land plant representatives and GenBank accession numbers of their chloroplast genomes.

\begin{tabular}{|c|c|c|c|c|}
\hline Order & Family & Genus & Species & Accession number \\
\hline Dipsacales & Lonicera & Lonicera & L. japonica & GQ997381-GQ997463 \\
\hline Ephedrales & Ephedraceae & Ephedra & E. equisetina & NC_011954 \\
\hline Ericales & Styracaceae & Styrax & S. grandiflorus & NC_030539.1 \\
\hline Ginkgoales & Ginkgoaceae & Ginkgo & G. biloba & DQ069337-DQ069702 EU016963-EU016982 \\
\hline Gnetales & Gnetaceae & Gnetum & G. parvifolium & NC_011942 KX385191 \\
\hline Gnetales & Gnetaceae & Gnetum & G. gnemon & KX385188 \\
\hline Gnetales & Gnetaceae & Gnetum & G. luofuense & KX234236 \\
\hline Gnetales & Gnetaceae & Gnetum & G. pendulum & KX385198 \\
\hline Gnetales & Gnetaceae & Gnetum & G. montanum & KX385196 \\
\hline Malpighiales & Salicaceae & Populus & P. trichocarpa & NC_009143 \\
\hline Malpighiales & Salicaceae & Salix & S. babylonica & NC_028350.1 \\
\hline Pinales & Pinaceae & Pinus & P. koraiensis & NC_004677 \\
\hline Poales & Poaceae & Sasa & S. veitchii & KU569975 \\
\hline Polypodiales & Dennstaedtiaceae & Pteridium & $P$. aquilinum & NC_014348 \\
\hline Gnetales & Welwitschiaceae & Welwitschia & W. mirabilis & NC_010654 \\
\hline
\end{tabular}


TABLE 3 | Photosynthetic characters of G. parvifolium and three species of land plant representatives measured in the wild. Data are means \pm standard deviation. Different letters in same column indicate significant difference $(p<0.05)$.

\begin{tabular}{|c|c|c|c|c|c|c|}
\hline Species & $\operatorname{Pn}\left(\mu \mathrm{mol} \mathrm{m} \mathrm{m}^{-2} \mathrm{~s}^{-1} \mathrm{CO}_{2}\right)$ & Gs $\left(\mathrm{mmol} \mathrm{m} \mathrm{m}^{-2} \mathrm{~s}^{-1}\right)$ & $\mathrm{Ci}\left(\mu \mathrm{mol} \mathrm{mol}{ }^{-1}\right)$ & $\operatorname{Tr}\left(g^{-2} h^{-1}\right)$ & VpdL (kPa) & Rc (\%) \\
\hline Gnetum parvifolium & $1.30 \pm 0.33 a$ & $0.01 \pm 0.00 a$ & $164.64 \pm 33.86 a$ & $0.20 \pm 0.39 a$ & $2.09 \pm 0.06 a$ & $57.86 \pm 6.83 a$ \\
\hline Lonicera japonica & $8.83 \pm 0.24 c$ & $0.08 \pm 0.01 b$ & $223.01 \pm 15.79 c$ & $1.39 \pm 0.04 c$ & $1.63 \pm 0.08 b$ & $49.96 \pm 4.11 c$ \\
\hline Pteris vittata & $5.80 \pm 0.41 b$ & $0.07 \pm 0.00 b$ & $360.26 \pm 11.08 d$ & $1.05 \pm 0.02 b$ & $1.52 \pm 0.04 b$ & $34.81 \pm 4.92 b$ \\
\hline Styrax confusus & $4.86 \pm 0.08 b$ & $0.11 \pm 0.00 b$ & $319.34 \pm 2.68 b$ & $1.87 \pm 0.1 b$ & $1.69 \pm 0.04 b$ & $33.17 \pm 1.82 \mathrm{~b}$ \\
\hline
\end{tabular}

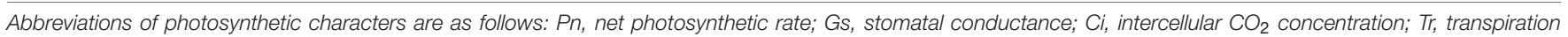
rate; VpdL, leaf water deficit; Rc, relative chlorophyll content.
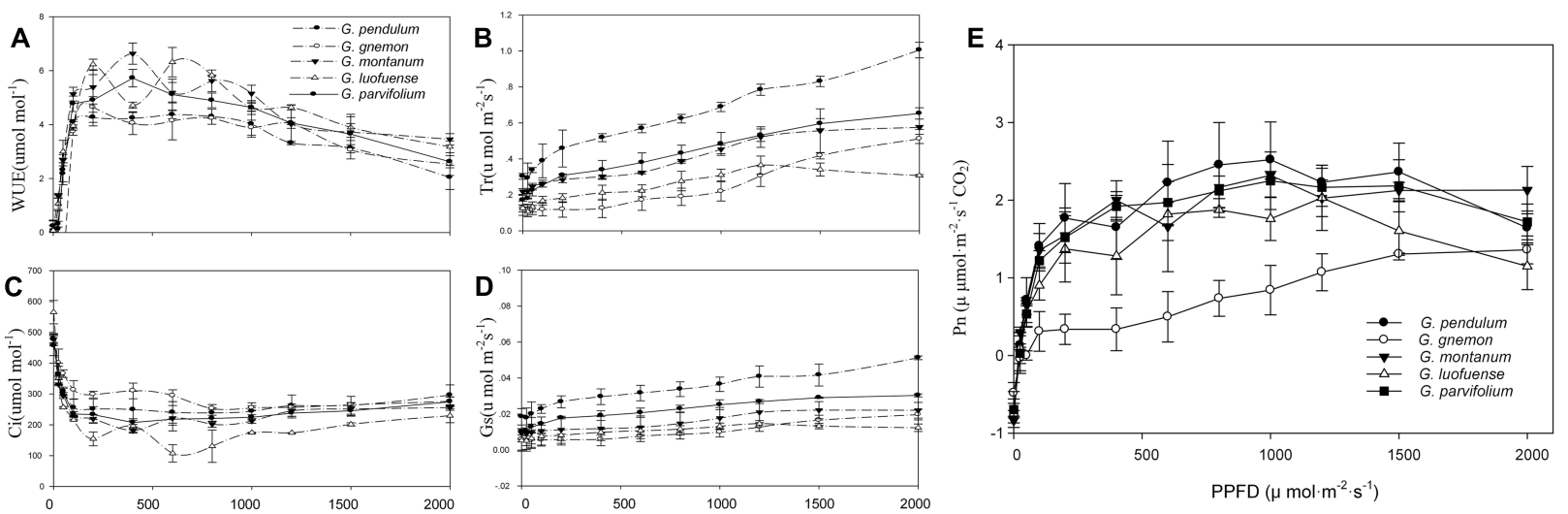

FIGURE 1 | Light-response curves of five Gnetum species. Y-axes represent five photosynthetic characters (mean values \pm standard deviation, $n=3$ ), i.e., (A) photosynthetic rate (Pn), (B) stomatal conductance (Gs), (C) intercellular $\mathrm{CO}_{2}$ concentration (Ci), (D) transpiration rate (Tr), and (E) water use efficiency (WUE). X-axis represents photosynthetic photon flux density (PPFD).
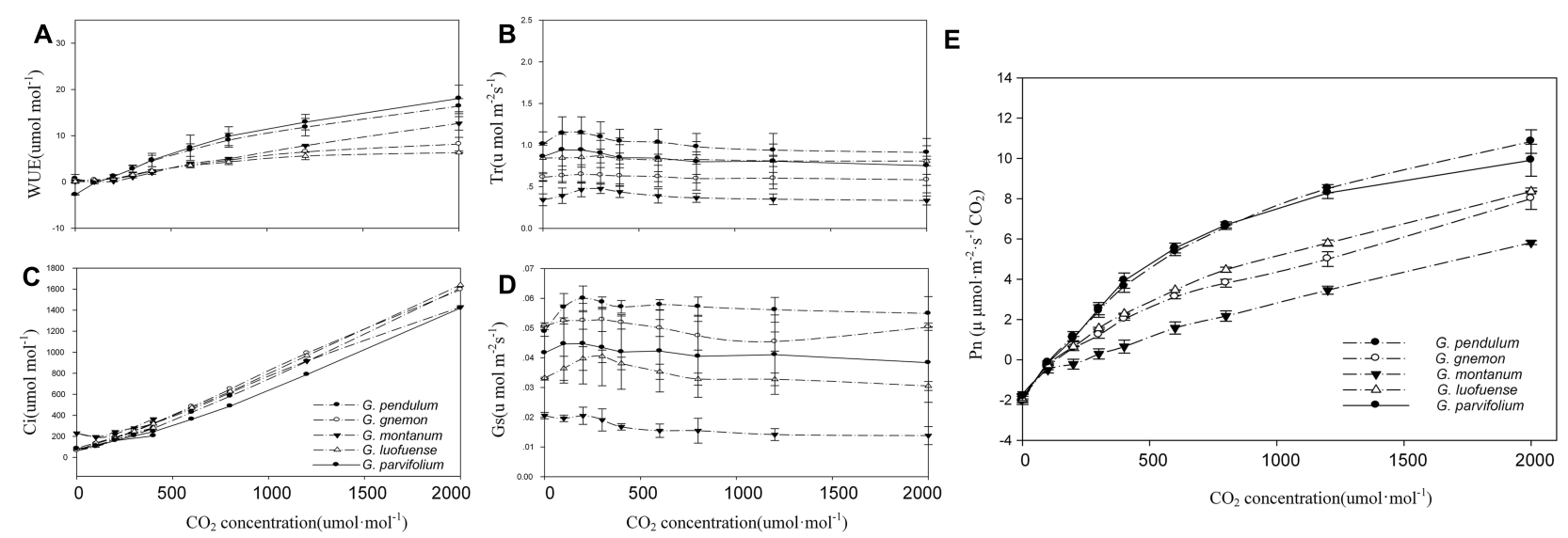

FIGURE 2 | $\mathrm{CO}_{2}$-response curves of five Gnetum species. Y-axes represent five photosynthetic characters (mean values \pm standard deviation, $n=3$ ), i.e., (A) photosynthetic rate (Pn), (B) stomatal conductance (Gs), (C) intercellular $\mathrm{CO}_{2}$ concentration (Ci), (D) transpiration rate (Tr), and (E) water use efficiency (WUE). X-axis represents $\mathrm{CO}_{2}$ concentration.

LSP, AmaxL, RdL, and AQY. The results indicated that the four lianoid species, in general, had greater photosynthetic potential than did G. gnemon (Table 4). Most of estimates for G. gnemon were significantly $(p<0.05)$ different from the estimates for other species (Table 4). G. pendulum had the highest photosynthetic capacity among the four lianoid species (Figures 1A-E).

\section{$\mathrm{CO}_{2}$-Response Curves of Gnetum}

As shown in the $\mathrm{CO}_{2}$-response curves, the $\mathrm{Pn}$ values among the five Gnetum species remarkably increased as the $\mathrm{CO}_{2}$ concentration increased, and reached a maximum value of $10.84 \mu \mathrm{mol} \mathrm{m} \mathrm{m}^{-2} \mathrm{~s}^{-1}$ (Figure 2A). G. parvifolium and G. pendulum had the highest Pn values in response to increased 
TABLE 4 | Photosynthetic characters of five Gnetum species in response to different light intensities. Data are means \pm standard deviation. Different letters in the same column indicate significant difference $(p<0.05)$.

\begin{tabular}{|c|c|c|c|c|c|}
\hline Species & $\operatorname{LCP}\left(\mu \mathrm{mol} \mathrm{m} \mathrm{m}^{-2} \mathrm{~s}^{-1}\right)$ & $\operatorname{LSP}\left(\mu \mathrm{mol} \mathrm{m}{ }^{-2} \mathrm{~s}^{1}\right)$ & AmaxL $\left(\mu \mathrm{mol} \mathrm{m}{ }^{-2} \mathrm{~s}^{-1} \mathrm{CO}_{2}\right)$ & $\operatorname{RdL}\left(\mu \mathrm{mol} \mathrm{m} \mathrm{m}^{-2} \mathrm{~s}^{-1}\right)$ & $A Q Y$ \\
\hline Gnetum gnemon & $54.27 \pm 12.88 b$ & $\geq 2000 b$ & $1.41 \pm 0.12 a$ & $0.24 \pm 0.01 \mathrm{ab}$ & $0.004 \pm 0.001 a$ \\
\hline Gnetum luofuense & $28.50 \pm 7.25 a$ & $1100.50 \pm 200.34 a$ & $2.11 \pm 0.31 b$ & $0.25 \pm 0.02 b$ & $0.010 \pm 0.002 b$ \\
\hline Gnetum montanum & $16.36 \pm 0.55 a$ & $950.25 \pm 100.17 a$ & $2.31 \pm 0.06 b$ & $0.17 \pm 0.02 a$ & $0.010 \pm 0.002 b$ \\
\hline Gnetum parvifolium & $28.06 \pm 12.43 b$ & $1099.67 \pm 172.63 a$ & $2.28 \pm 0.32 b$ & $0.28 \pm 0.13 a$ & $0.010 \pm 0.004 a$ \\
\hline Gnetum pendulum & $16.39 \pm 3.36 a$ & $950.25 \pm 100.17 a$ & $2.75 \pm 0.32 c$ & $0.16 \pm 0.09 a$ & $0.010 \pm 0.002 b$ \\
\hline
\end{tabular}

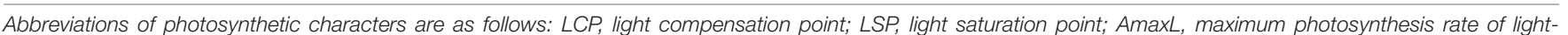
response; RdL, dark respiration rate of light-response; $A Q Y$, apparent quantum yield.

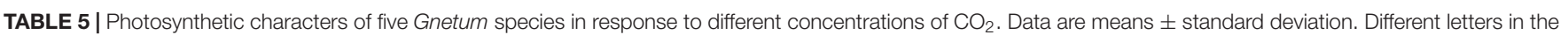
same column indicate significant difference $(p<0.05)$.

\begin{tabular}{|c|c|c|c|c|c|}
\hline Species & $\mathrm{CCP}\left(\mu \mathrm{mol} \mathrm{mol}{ }^{-1}\right)$ & $\operatorname{CSP}\left(\mu \mathrm{mol} \mathrm{mol}{ }^{-1}\right)$ & AmaxC $\left(\mu \mathrm{mol} \mathrm{m}{ }^{-2} \mathrm{~s}^{-1} \mathrm{CO}_{2}\right)$ & $\mathrm{CE}\left(\mu \mathrm{mol} \mathrm{m}{ }^{-2} \mathrm{~s}^{-1}\right)$ & $\operatorname{RdC}\left(\mu \mathrm{mol} \mathrm{m} \mathrm{m}^{-2} \mathrm{~s}^{-1}\right)$ \\
\hline Gnetum gnemon & $167.55 \pm 5.20 a$ & $\geq 2000$ & $8.00 \pm 0.02 b$ & $0.009 \pm 0.0004 b$ & $1.582 \pm 0.11 a b$ \\
\hline Gnetum luofuense & $155.82 \pm 17.05 a$ & $\geq 2000$ & $8.36 \pm 1.14 b$ & $0.010 \pm 0.0004 b$ & $1.614 \pm 0.23 a b$ \\
\hline Gnetum montanum & $260.66 \pm 54.70 b$ & $\geq 2000$ & $5.82 \pm 0.12 a$ & $0.006 \pm 0.001 a$ & $1.401 \pm 0.06 a$ \\
\hline Gnetum parvifolium & $133.04 \pm 11.31 b$ & $\geq 2000$ & $10.71 \pm 0.80 a$ & $0.014 \pm 0.001 a$ & $1.810 \pm 0.06 a$ \\
\hline Gnetum pendulum & $129.12 \pm 11.08 a$ & $\geq 2000$ & $10.84 \pm 0.83 c$ & $0.014 \pm 0.001 c$ & $1.801 \pm 0.05 b$ \\
\hline
\end{tabular}

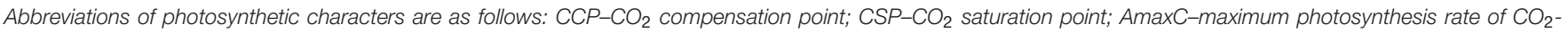
response; CE-carboxylation efficiency; $\mathrm{RdC}$-dark respiration rate of $\mathrm{CO}_{2}$-response.

$\mathrm{CO}_{2}$, while G. montanum had the lowest (Table 5). The fitting degree $\left(\mathrm{R}^{2}\right)$ ranged from 0.98 to 0.99 among the five species of Gnetum, indicating a very good fit by cubic polynomial equations.

The five Gnetum species showed similar trends in $\operatorname{Tr}$ and Gs in response to increasing $\mathrm{CO}_{2}$ concentrations (Figure 2). G. pendulum had the highest $\mathrm{Tr}$ and Gs values across the studied range of $\mathrm{CO}_{2}$ concentrations, while G. montanum had the lowest. The results revealed that an increased concentration of $\mathrm{CO}_{2}$ in air could increase the $\mathrm{Ci}$ and WUE, but did not significantly affect $\mathrm{Tr}$ and Gs in Gnetum (Figure 2B,E).

\section{Monthly Variations in Photosynthetic Characters in Gnetum and Other Seed Plants}

The Tr, Pn, Gs, Vpdl, and Rc remained unchanged or only slightly changed from June to September among the five Gnetum species. However, the $\mathrm{Ci}$ values showed dramatic variations over this period of time (Figure 3 ). The values of photosynthetic characters such as $\mathrm{Pn}$, Tr, and Gs were much lower in the five species of Gnetum than in the other seed plant representatives, i.e., P. tomentosa, P. tabuliformis, S. babylonica, and $S$. argenteostriata. However, the differences were minor among these seed plant groups in terms of $\mathrm{Ci}, \mathrm{Vpdl}$, and $\mathrm{Rc}$ (Figure 3).

\section{Principal Component and Cluster Analyses of Photosynthetic Characters}

The results of PCA analyses (Figure 4) revealed that $87.0 \%$ of the variance in the data could be explained by the first two principal components, i.e., PC1 and PC2 (explaining 64.8\% and $22.2 \%$, respectively). The photosynthetic characters ( $\mathrm{Pn}$, $\mathrm{Tr}, \mathrm{Ci}, \mathrm{Gs}$, and Vpdl) of the five Gnetum species clustered separately from those of other seed plant representatives. In addition, the photosynthetic characters of G. parvifolium measured in the wild were strongly differentiated from those of Gnetum species cultivated in the greenhouse (Figure 4).

We compared the results of six clustering methods and found that the UPGMA method achieved the highest score of cophenetic correlation (0.89) (Figure 5; Supplementary Figure S1). Regardless of the clustering method used, the results suggested that photosynthetic characters of the five Gnetum species were similar to those of Ginkgo but considerably different from those of angiosperms and conifer representatives.

\section{Comparison of Chloroplast Genomes and Phylogenetic Reconstruction}

Comparisons among cpDNAs of Gnetum and other seed plant representatives (Figure 6) revealed that 17 coding genes were absent from the cpDNAs of Gnetum (Braukmann et al., 2009). Among the absent genes were $c l p P$ (encoding the ATP-dependent Clp protease proteolytic subunit), all 11 genes encoding NADH dehydrogenase, $a c c D$, rpl23 (encoding ribosomal protein L23), rpl32 (encoding ribosomal protein L32), rps15, and rps16. We found also that 15 and 14 genes were absent from the cpDNAs of Ephedra and Welwitschia, respectively. Specimens representing angiosperms formed a clade, which was sister to the clade representing gymnosperms, within which Ginkgo biloba was sister to the remaining group of species in this clade. The Gnetales were placed as the sister clade to the Pinaceae. However, the pattern of the cluster analyses based on photosynthetic characters seemed incongruent with the topology of the present phylogeny of the selected seed plants (Supplementary Figure S2). One possible explanation may be that insufficient plant species were 


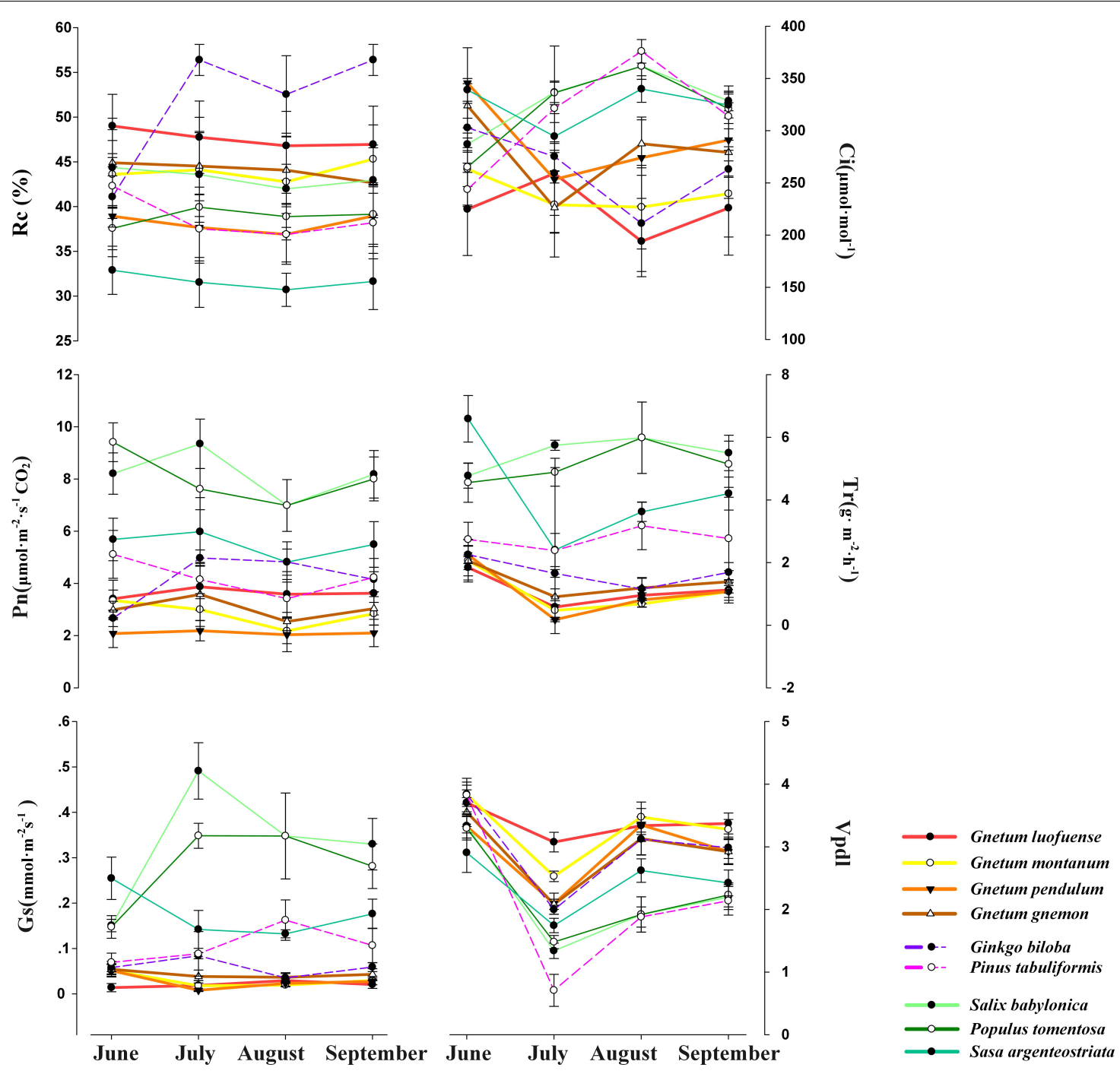

FIGURE 3 | Comparisons of photosynthetic characters measured from June to September among four Gnetum species and five seed plant representatives. X-axes represent six photosynthetic characters (mean values \pm standard deviation, $n=3$ ), i.e., relative chlorophyll $(\mathrm{Rc})$, intercellular $\mathrm{CO}_{2}$ concentration $(\mathrm{Ci})$, photosynthetic rate $(\mathrm{Pn})$, transpiration rate $(\mathrm{Tr})$, stomatal conductance (Gs), and leaf water deficit (Vpdl).

included in the analyses. However, we note that the aim of constructing this tree was not to explain the phylogeny in this study, as mentioned in the method.

\section{DISCUSSION}

\section{Low Values for Photosynthetic Characters Within Gnetum}

We conducted these experiments in the wild and in the greenhouse where the three most important factors for photosynthesis, i.e., light intensity, $\mathrm{CO}_{2}$ concentration, and temperature, were almost similar. The values of the photosynthetic characters $\mathrm{Pn}, \mathrm{Gs}$, and $\mathrm{Tr}$ were slightly lower for G. parvifolium in the wild than for G. parvifolium in the greenhouse (Table 3, Figure 1). Nevertheless, the photosynthetic features of G. parvifolium in the wild and in the greenhouse did not exhibit significant differences under the similar light conditions (for example, under high light intensity). We found consistent differences in photosynthetic characters between the arborescent species G. gnemon and Chinese lianoid species. In general, the capacities to utilize different light intensities were higher in lianoid species. Our results are also consistent with those of previous studies that detected low Pn, Gs, and Tr in Gnetum (Feild and Balun, 2008; Celis and Avalos, 2013). For example, the Pn was found to be $2.1-2.4 \mu \mathrm{mol} \mathrm{m}{ }^{-2} \mathrm{~s}^{-1} \mathrm{CO}_{2}$ in seedlings of G. leyboldii (Celis and Avalos, 2013), which is at the higher end of the range detected in the five Gnetum species we studied (Figure 1).

In the PCA analysis, we found that estimates of Gs made the largest contribution to PC1, followed by estimates of $\operatorname{Tr}$ and $\mathrm{Pn}$, reflecting the remarkable differences in 


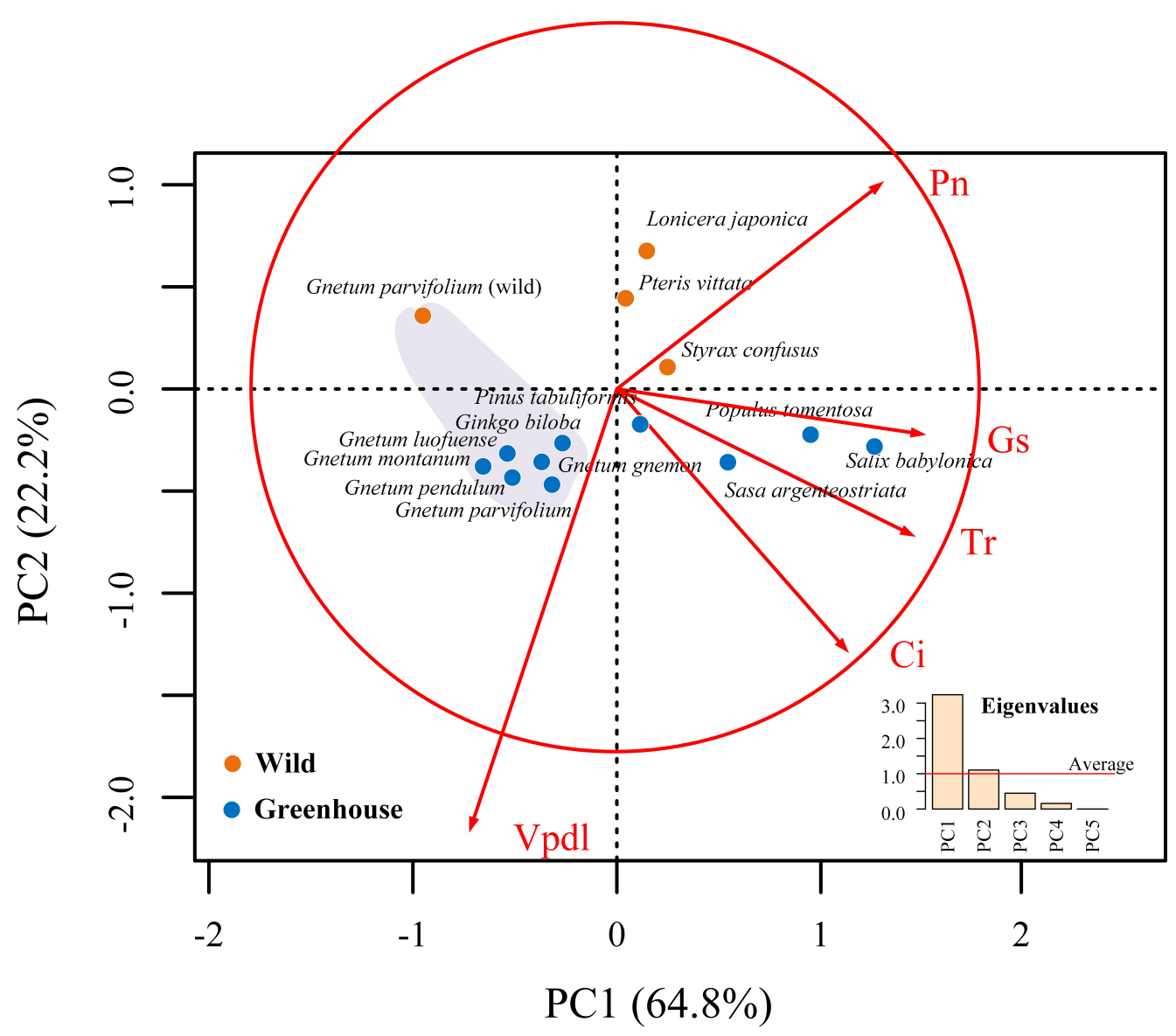

FIGURE 4 | Principal component analyses (PCA) of five photosynthetic characters, i.e., net photosynthetic rate (Pn), transpiration rate (Tr), intercellular $\mathrm{CO}_{2}$ concentration (Ci), stomatal conductance (Gs), and leaf water deficit (Vpdl) among five Gnetum species and other seed plant representatives. Photosynthetic characters detected in the wild (orange) and in the greenhouse (blue). In PCA ordination, red circle represents the best-fit equilibrium contribution. Five red lines indicate that contribution of certain photosynthetic character is greater than average value. At the corner on right, different eigenvalues from PCA characters (PC1-PC5) are shown under Kaiser-Guttman criterion.

photosynthetic parameters between Gnetum and other land plants. Low values of $G$ s and $\operatorname{Tr}$ might reflect the restricted functions of syndetocheilie-type stomata in Gnetum leaves (Takeda, 1913). The Vpdl accounted for the majority of differentiation along PC2 and distinguished the photosynthetic characters of G. parvifolium measured in the field from those of other Gnetum species measured in the greenhouse. These differences might be due to differences in soil water availability and evaporationtranspiration rates under the two conditions. In addition, atmosphere and biota have likely co-evolved throughout history (Beerling et al., 2001; Igamberdiev and Lea, 2006; Franks and Beerling, 2009). High $\mathrm{CO}_{2}$ and sub-ambient $\mathrm{O}_{2}$ in the atmosphere can affect patterns of plant distribution and evolution (Fukao and Baileyserres, 2004; Wang D. et al., 2012; Haworth et al., 2013). Accordingly, we suggest that the photosynthetic capacities of extant Gnetum are probably inherited from their ancestors that evolved under the high global temperatures and $\mathrm{CO}_{2}$ density in the late Cretaceous to early Cenozoic (Zachos et al., 2001). These characteristics may thus provide an advantage to some species of this genus under scenarios of further global warming.

\section{Comparisons of Photosynthetic Characters and Chloroplast Genomes Between Gnetum and Other Seed Plants}

The results of multivariate analyses revealed that some photosynthetic characters of Gnetum (Pn, Gs, Tr) differ markedly from those of other seed plants. Among the gymnosperms, G. biloba showed significantly different Pn, $\mathrm{Tr}$, and Gs compared with those of Gnetum seedlings (Figure 3). This result was consistent with experimental data showing that 2-year-old G. biloba seedlings had a higher photosynthetic capacity than that of Gnetum (Zhang et al., 2005). The estimated values of photosynthetic characters were significantly larger in $P$. tabuliformis than in Gnetum, consistent with studies on other Pinus species (Di, 2009; Liu et al., 2009; Wang Z.X. et al., 2012). This is quite surprising, because conifers are 


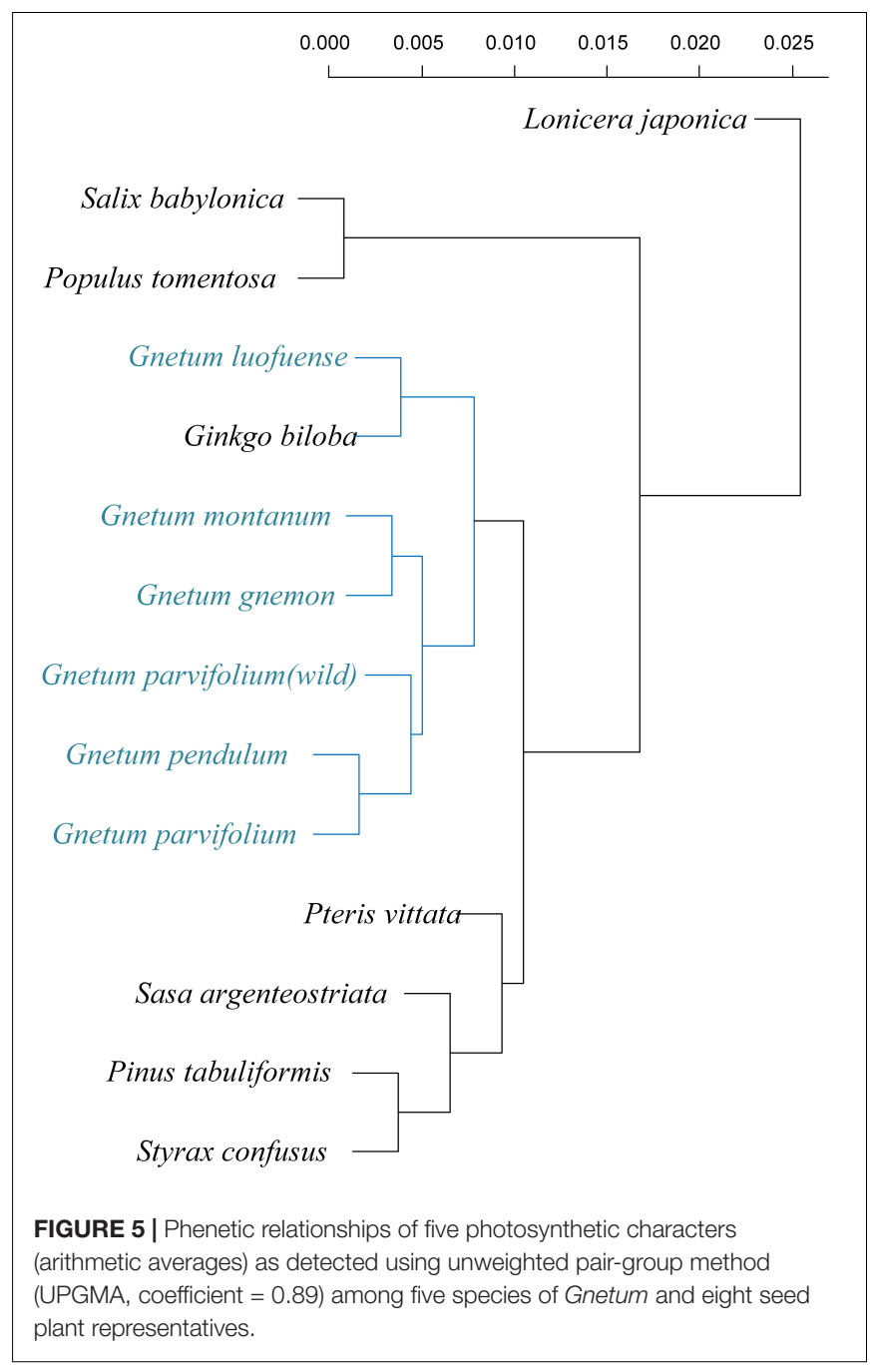

characterized by lancelet or needle-shaped leaves that have a low Pn. However, their Pn was still higher than that of Gnetum leaves, which have eudicot morphology and pinnate leaf venation. The values of $\mathrm{Pn}, \mathrm{Tr}$, and Gs were consistently lower in G. biloba and P. tabuliformis than in the selected angiosperms (Figure 3), indicating that a low rate of photosynthesis might be a common characteristic of gnetophytes, conifers, and other gymnosperms. This topic should be investigated further in future studies.

The relationships among photosynthetic characters of other gymnosperms, comprising main lineages of conifers, cycads, Ephedra and Welwitschia, remain poorly understood. Morphologically, Ephedra has extremely reduced, small, linear leaves, and Welwitschia has giant strap-like leaves with numerous parallel longitudinal veins (Yang et al., 2015). Nevertheless, on the basis of the genomic data and morphological characters, we predict that low photosynthetic capacities could also characterize the two gnetalean genera whose habitats are in arid and semiarid areas of the world. Therefore, the ancestral status of photosynthetic characters in the Gnetales remains an open question.
We found that the values of photosynthetic characters, e.g., Pn, Tr, and Gs were significantly lower in Gnetum than in co-occurring lianoid angiosperms both in the wild and in the greenhouse. This can probably be ascribed to the different gross morphology and anatomical structures of Gnetum leaves. Compared with angiosperms, Gnetum and ferns have significantly lower densities of leaf veins (Zwieniecki and Boyce, 2014b). In addition, the veins in Gnetum leaves are arranged differently from veins in lianoid angiosperms, probably resulting in low efficiency of hydraulic transportation (Zwieniecki and Boyce, 2014a).

To adapt to low-light conditions beneath canopies in tropical forests, seedlings of lianoid angiosperms usually have a low light compensation and light saturation point (Yuan et al., 2016). After reaching maturity and being exposed to high-intensity light at the highest levels of canopies, seedlings of lianoid angiosperms can shift to high photosynthetic capacities and effective hydraulic conductance (Carter and Teramura, 1988). However, this is not the case in Gnetum. The results of the present study showed no significant differences in photosynthetic characters between Gnetum adults and seedlings. Therefore, the photosynthetic characters of Gnetum are ecophysiologically different from those of lianoid angiosperms. Nevertheless, the results of $\mathrm{CO}_{2}$ response experiment (Figure 2) revealed that Gnetum might have some potential for higher efficiency of photosynthesis. The maximum $\mathrm{Pn}$ value along the $\mathrm{CO}_{2}$ response curve was higher in Gnetum than in the co-occurring lianoid angiosperms. This result indicated that certain photosynthetic features of Gnetum have undergone evolution in parallel with those of angiosperms as an adaptation to tropical and subtropical forest environments where high humidity, high density of trunks or stems, and strong competition among plants are the prevailing conditions. Although Gnetum shares tropical biomes and habitats with lianoid angiosperms, Gnetum species do not show highly opportunistic and light-demanding ecophysiology. An intriguing question to address is the association between the ontogenetic flexibility of photosynthetic efficiency in angiosperms and the evolutionary success of this incredibly large clade of seed plants.

A previous study of Wu et al. (2009) shows that gnetophyte, including G. parvifolium in the genus of Gnetum, has specific loss of 18 genes common to cpDNAs of other land plants. Meanwhile, all $11 n d h$ genes encoding NADPH dehydrogenases are reported to be absent in the measured four Gnetum species (G. gnemon, G. leyboldii Tul., G. ula Brongn. and Gnetum sp.) (Braukmann et al., 2009). In the present study, we focused on investigating the relationship between low photosynthetic characters and gene loss of cpDNAs in Gnetum, based on the previous findings (Braukmann et al., 2009; Wu et al., 2009; Hou et al., 2016). The result showed that 17 coding genes are absent from cpDNAs of five Gnetum species, which has used in the work of Hou et al. (2016), compared with those selected seed plant representatives (Figures 5 and 6; Supplementary Figure S2). Among the lost genes are those encoding subunits of ATP synthase, cytochrome b/f complex, photosystem I and II, and the large subunit of Rubisco, all of 

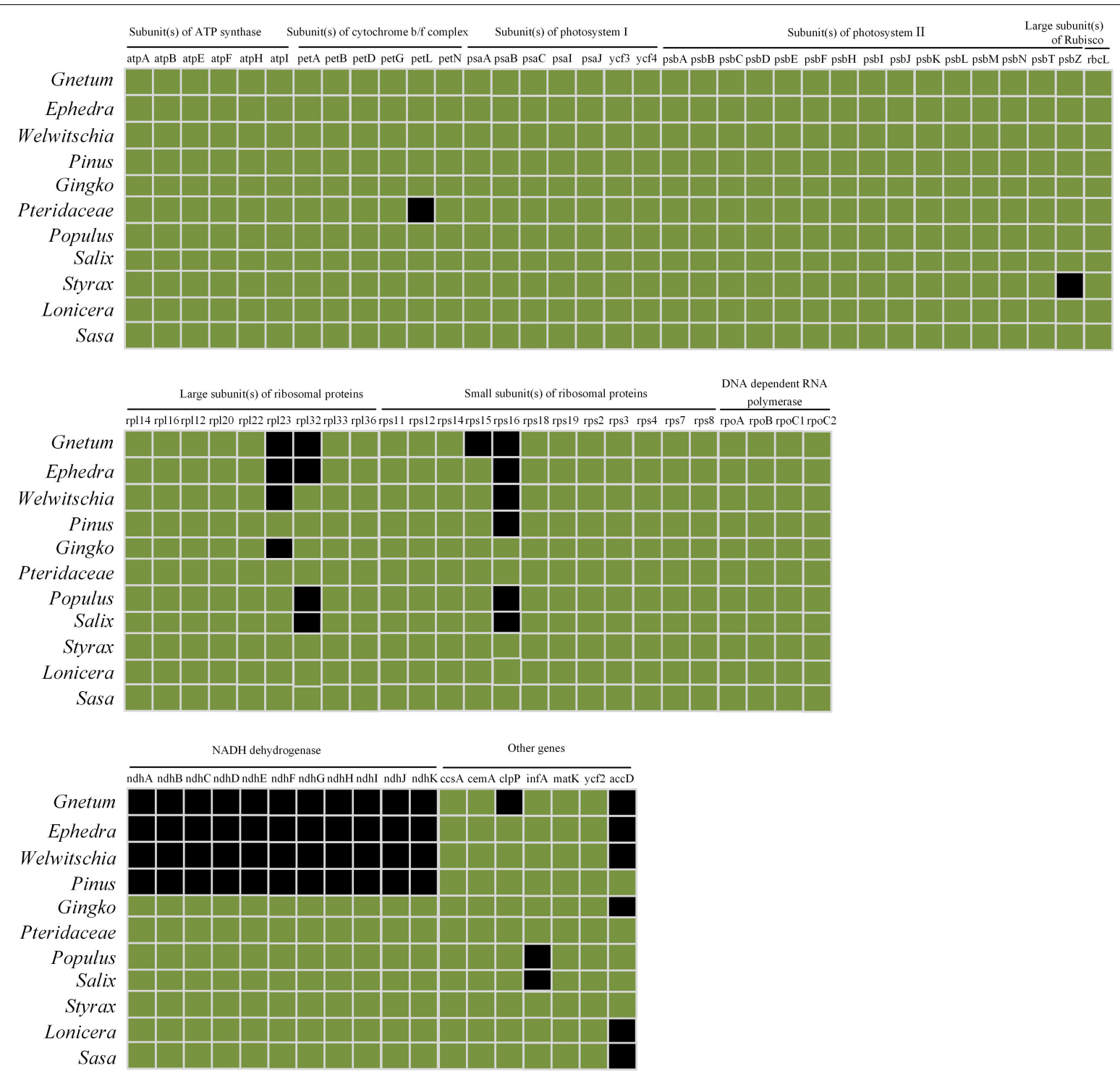

FIGURE 6 | Comparison of coding genes among chloroplast genomes of Gnetales (i.e., Gnetum, Ephedra, and Welwitschia) and eight seed plant representatives including Dipsacales, Ericales, Ginkgoales, Malpighiales, Pinales, Poales, and Pteridales. Genes shown in black are absent from chloroplast genomes.

which are involved in particular pathways of photosynthesis (Salah et al., 2016). In addition, we found that all genes encoding NADPH dehydrogenases are absent from the cpDNAs of Gnetum. These genes are also absent from cpDNAs of Pinus (Braukmann et al., 2009; Wu et al., 2009), suggesting support for the Gnepine hypothesis that places the Gnetales as the sister lineage of Pinaceae. NADPH dehydrogenases are an important part of the membrane protein complex that mediates the uptake of $\mathrm{CO}_{2}$, transport of photosystem I-dependent cyclic electrons, and cellular respiration (Ueda et al., 2012; Yamori et al., 2015). As regards to these photosynthetic functions, therefore, the absence of genes encoding NADPH probably affects the efficiency of energy conversion similarly in both Gnetum and Pinus (Wu et al., 2009). However, we should not overlook the closer relationship between Gnetum and Ginkgo than between Gnetum and Pinus, as suggested by PCA and cluster analyses of the whole set of photosynthetic characters used in ourstudy (Figures 4 and 5). These results indicate the likely low impact of the lack of these NADPH genes and their functions on the overall photosynthetic characters of plants, at least at the deep evolutionary scale of the three main gymnosperm lineages.

\section{CONCLUSION}

The results of this study further corroborate that Gnetum species have low Pn, Gs, and Tr. In addition, we found that multiple chloroplast genes that are believed to be essential for photosynthesis are absent from Gnetum, probably resulting 
in its particular evolutionary history. The other gnetophytes, Ephedra and Welwitschia, which have been adapted to arid and semiarid living habitats, lack the same chloroplast genes. This finding suggests that low photosynthetic capacity may also be a characteristic of these two genera, and the unique evolutionary history could be a feature of the entire group. Nevertheless, further research is required to investigate the molecular mechanisms underlying the low photosynthetic capacity in gnetophytes. It will also be interesting to compare gross morphology and anatomical structures of pinnate-veined leaves and vessels in association with transcriptome differences between Gnetum and angiosperms. Accordingly, these analyses of photosynthetic, physiological, and morphological characters of Gnetum in combination with the particular structure of its cpDNA provide a new perspective on the evolutionary history of the Gnetales.

\section{AUTHOR CONTRIBUTIONS}

$\mathrm{ND}$ and $\mathrm{CH}$ make the major contribution to this article, and other authors also make considerable contributions to this article.

\section{FUNDING}

This work was supported by the Research Fund of Key Laboratory of Tree Breeding and Cultivation of State Forestry Administration (ZDRIF201707), the Special Fund for State Key Laboratory of Tree Genetics and Breeding (TGB2013012), the

\section{REFERENCES}

Beerling, D. J., Osborne, C. P., and Chaloner, W. G. (2001). Evolution of leaf-form in land plants linked to atmospheric $\mathrm{CO} 2$ decline in the Late Palaeozoic era. Nature 410, 352-354. doi: 10.1038/35066546

Braukmann, T. W., Kuzmina, M., and Stefanoviæ, S. (2009). Loss of all plastid ndh genes in Gnetales and conifers: extent and evolutionary significance for the seed plant phylogeny. Curr. Genet. 55, 323-337. doi: 10.1007/s00294-009-0249-7

Burleigh, J. G., and Mathews, S. (2004). Phylogenetic signal in nucleotide data from seed plants: implications for resolving the seed plant tree of life. Am. J. Bot. 91, 1599-1613. doi: 10.3732/ajb.91.10.1599

Carter, G. A., and Teramura, A. H. (1988). Vine photosynthesis and relationships to climbing mechanics in a forest understory. Am. J. Bot. 75, 1011-1018. doi: 10.1002/j.1537-2197.1988.tb08808.x

Celis, G., and Avalos, G. (2013). Acclimation of seedlings of Gnetum leyboldii Tul. (Gnetaceae) to light changes in a tropical rain forest. Rev. Biol. Trop. 61, 1859-1868.

Chen, Z. D., Yang, T., Lin, L., Lu, L. M., Li, H. L., Sun, M., et al. (2016). Tree of life for the genera of Chinese vascular plants. J. Syst. Evol. 54, 277-306. doi: $10.1111 /$ jse.12219

Crane, P. R. (1985). Phylogenetic analysis of seed plants and the origin of angiosperms. Ann. Mo. Bot. Gard. 72, 716-793. doi: 10.2307/2399221

Deng, N., Chang, E., Li, M., Ji, J., Yao, X., Bartish, I. V., et al. (2016). Transcriptome characterization of Gnetum parvifolium reveals candidate genes involved in important secondary metabolic pathways of flavonoids and stilbenoids. Front. Plant Sci. 7:174. doi: 10.3389/fpls.2016.00174

Deng, N., Liu, C., Chang, E., Ji, J., Yao, X., Yue, J., et al. (2017). High temperature and UV-C treatments affect stilbenoid accumulation and related
Fund of National Non-profit Research Institutions of CAF (RIF2013-12) and the Special Fund for Hunan Forestry Science and Technology (XLK201812).

\section{ACKNOWLEDGMENTS}

We thank Jennifer Smith, Ph.D., from Liwen Bianji, Edanz Group China (www.liwenbianji.cn/ac), for editing the English text of a draft of this manuscript. We also thank two reviewers for valuable comments on the text.

\section{SUPPLEMENTARY MATERIAL}

The Supplementary Material for this article can be found online at: https://www.frontiersin.org/articles/10.3389/fpls.2019.00039/ full\#supplementary-material

FIGURE S1 | Cluster analyses of five photosynthetic characters i.e., net photosynthetic rate $(\mathrm{Pn})$, transpiration rate $(\mathrm{Tr})$, intercellular $\mathrm{CO}_{2}$ concentration (Ci), stomatal conductance (Gs), and leaf water deficit (Vpdl) among five Gnetum species and eight representatives of other land plants using six different methods. Numbers in red are values of cophenetic correlation coefficient.

FIGURE S2 | Phylogenetic tree inferred from literature showing evolutionary relationships across seed plants and within Gnetum based on chloroplast genome data (Won and Renner, 2006; Wu et al., 2007; Hou et al., 2016), and presence/absence of particular genes in chloroplast genomes of seed plants. Genes shown in black in right panel are absent. For complete list of genes in panel, see Supplementary Table S1. Complete chloroplast genome sequence data for correspondent taxa were obtained from GenBank.

TABLE S1 | Complete list of protein-coding genes in chloroplast genomes included in this study. See Table 2 for GenBank accession numbers. gene expression levels in Gnetum parvifolium. Electro. J. Biotechnol. 25, 43-49. doi: 10.1016/j.ejbt.2016.11.001

Di, X. Y. (2009). Effects of soil water stress on photosynthetic characteristics in five provenances of Chinese Pine (Pinus tabulaeformis Carr.). Bull. Bot. Res. 29, 202-203.

Doyle, J. A. (1998). Molecules, morphology, fossils, and the relationship of angiosperms and Gnetales. Mol. Phylogenet. Evol. 9, 448-462. doi: 10.1006/ mpev.1998.0506

Doyle, J. A., and Donoghue, M. J. (1986). Seed plant phylogeny and the origin of angiosperms: an experimental cladistic approach. Bot. Rev. 52, 321-431. doi: $10.1007 / \mathrm{BF} 02861082$

Doyle, J. A., and Donoghue M. J. (1992). Fossils and seed plant phylogeny reanalyzed. Brittonia 44, 89-106. doi: 10.2307/2806826

Farquhar, G. D., Caemmerer, S. V., and Berry, J. A. (2001). Models of photosynthesis. Plant Physiol. 125, 42-45. doi: 10.1104/pp.125.1.42

Feild, T. S., and Balun, L. (2008). Xylem hydraulic and photosynthetic function of Gnetum (Gnetales) species from Papua New Guinea. New Phytol. 177, 665-675. doi: 10.1111/j.1469-8137.2007.02306.x

Franks, P. J., and Beerling, D. J. (2009). Maximum leaf conductance driven by CO2 effects on stomatal size and density over geologic time. Proc. Natl. Acad. Sci. U.S.A. 106, 10343-10347. doi: 10.1073/pnas.0904209106

Friedman, W. E. (1998). The evolution of double fertilization and endosperm: an "historical" perspective. Sex. Plant Reprod. 11, 6-16. doi: 10.1007/ s004970050114

Fukao, T., and Baileyserres, J. (2004). Plant responses to hypoxia - is survival a balancing act? Trends Plant Sci. 9, 449-456. doi: 10.1016/j.tplants.2004.07.005

Gong, Y. B., Yang, M., Vamosi, J. C., Yang, H. M., Mu, W. X., Li, J. K., et al. (2016). Wind or insect pollination? Ambophily in a subtropical gymnosperm Gnetum 
parvifolium (Gnetales). Plant Spec. Biol. 31, 272-279. doi: 10.1111/1442-1984. 12112

Guttman, L. (1954). Some necessary conditions for common-factor analysis. Psychometrika 19, 149-161. doi: 10.1007/BF02289162

Haworth, M., Elliott-Kingston, C., and Mcelwain, J. C. (2013). Co-ordination of physiological and morphological responses of stomata to elevated CO2 in vascular plants. Oecologia 171, 71-82. doi: 10.1007/s00442-0122406-9

Hou, C., Humphreys, A. M., Thureborn, O., and Rydin, C. (2015). New insights into the evolutionary history of Gnetum (Gnetales). Taxon 64, 239-253. doi: $10.12705 / 642.12$

Hou, C., Wikström, N., Strijk, J. S., and Rydin, C. (2016). Resolving phylogenetic relationships and species delimitations in closely related gymnosperms using high-throughput NGS, Sanger sequencing and morphology. Plant Syst. Evol. 302, 1345-1365. doi: 10.1007/s00606-016-1335-1

Ickert Bond, S. M., and Renner, S. S. (2016). The Gnetales: recent insights on their morphology, reproductive biology, chromosome numbers, biogeography, and divergence times. J. Syst. Evol. 54, 1-16. doi: 10.1111/jse. 12190

Ickert Bond, S. M., and Wojciechowski, M. F. (2004). Phylogenetic relationships in Ephedra (Gnetales): evidence from nuclear and chloroplast DNA sequence data. Syst. Bot. 29, 834-849. doi: 10.1600/036364404 2451143

Igamberdiev, A. U., and Lea, P. J. (2006). Land plants equilibrate O2 and CO2 concentrations in the atmosphere. Photosynth. Res. 87, 177-194. doi: 10.1007/ s11120-005-8388-2

Kaiser, H. F. (2016). The application of electronic computers to factor analysis. Educ. Psychol. Meas. 20, 141-151. doi: 10.1177/00131644600200 0116

Katoh, K., Rozewicki, J., and Yamada, K. D. (2017). MAFFT online service: multiple sequence alignment, interactive sequence choice and visualization. Brief. Bioinform. 06:bbx108. doi: 10.1093/bib/bbx108

Liu, J., Liang, J. S., Wang Jian, M., Chen, X. M., Yang, Z. X., and Chen, H. (2009). Diurnal change of photosynthetic characteristics and response to light intensity of Pinus kesiya royle ex Gordon var.langbianensis. For. Res. 22, 677-682.

Mao, J., Zhou, F., Liu, T., Wu, Z., Zhong, T., Liu, C., et al. (2017). The complete chloroplast genome of Gnetum montanum and sequence analysis. DNA Seq. 28, 409-410. doi: 10.3109/19401736.2015.1127368

Markgraf, F. (1930). Monographie der Gattung Gnetum. Ser. 3 Bull. Jar. Bot. Buitenz. 10, 407-511.

Markgraf, F. (1951). Gnetaceae. Flora Malesiana ser. 14, 336-347.

Markgraf, F. (1965). New discoveries of Gnetum in tropical America. Ann. Mol. Bot. Gard. 52, 379-386. doi: 10.2307/2394800

Mayor, C., Brudno, M., Schwartz, J. R., Poliakov, A., Rubin, E. M., Frazer, K. A., et al. (2000). VISTA: visualizing global DNA sequence alignments of arbitrary length. Bioinformatics 16, 1046-1047. doi: 10.1093/bioinformatics/ 16.11.1046

Palliotti, A., and Cartechini, A. (2015). Photosynthetic light response curves in relation to illumination of adaxial and abaxial surfaces of sun and shade leaves of Vitis vinifera L. Antimicrob. Agents Chem. 40, 174-184.

Price, R. A. (1996). Systematics of the Gnetales: a review of morphological and molecular evidence. Int. J. Plant Sci. 157, 40-49. doi: 10.1086/297402

Ran, J. H., Shen, T. T., Wang, M. M., and Wang, X. Q. (2018). Phylogenomics resolves the deep phylogeny of seed plants and indicates partial convergent or homoplastic evolution between Gnetales and angiosperms. Proc. R. Soc. B. 285:20181012. doi: 10.1098/rspb.2018.1012

Ruhfel, B. R., Gitzendanner, M. A., Soltis, P. S., Soltis, D. E., and Burleigh, J. G. (2014). From algae to angiosperms-inferring the phylogeny of green plants (Viridiplantae) from 360 plastid genomes. BMC Evol. Biol. 14:23. doi: 10.1186/ 1471-2148-14-23

Rydin, C. and Korall, P. (2009). Evolutionary relationships in Ephedra (Gnetales), with implications for seed plant phylogeny. Int. J. Plant Sci. 170, 1031-1043. doi: $10.1086 / 605116$

Salah, A., Khalifa, N. S., Shehata, M. M., Abdelsattar, M. T., and Ibrahim, M. (2016). Deciphering the effects of temperature stress on RuBisCO large subunit and its complex assembly. Egypt. J. Exp. Biol. 12, 9-19.

Soltis, D. E., Soltis, P. S., and Zanis, M. J. (2002). Phylogeny of seed plants based on evidence from eight genes. Am. J. Bot. 89, 1670-1681. doi: 10.3732/ajb.89.10. 1670
Stamatakis, A. (2006). RAxML-VI-HPC: maximum likelihood-based phylogenetic analyses with thousands of taxa and mixed models. Bioinformatics 22, 2688-2690. doi: 10.1093/bioinformatics/\{\break\}btl446

Takeda, H. (1913). Development of the stoma in Gnetum gnemon. Ann. Bot. 27, 365-366. doi: 10.1093/oxfordjournals.aob.a089464

Ueda, M., Kuniyoshi, T., Yamamoto, H., Sugimoto, K., Ishizaki, K., Kohchi, T., et al. (2012). Composition and physiological function of the chloroplast NADH dehydrogenase-like complex in Marchantia polymorpha. Plant J. 72, 683-693. doi: 10.1111/j.1365-313X.2012.05115.x

Wan, T., Liu, Z. M., Li, L. F., Leitch, A. R., Leitch, I. J., Lohaus, R., et al. (2018). A genome for gnetophytes and early evolution of seed plants. Nat. Plants 4, 82-89. doi: 10.1038/s41477-017-0097-2

Wang, D., Heckathorn, S. A., Wang, X., and Philpott, S. M. (2012). A meta-analysis of plant physiological and growth responses to temperature and elevated CO2. Oecologia 169, 1-13. doi: 10.1007/s00442-011-2172-0

Wang, Z. X., Wei, H., Li, C. X., Lv, Q., Zhou, Q., Gao, W., et al. (2012). Effect of soil moisture variations on photosynthetic characteristics of Slash Pine Seedlings. Acta Bot. Boreali-Occidentalia Sin. 32, 980-987.

Won, H., and Renner, S. S. (2006). Dating dispersal and radiation in the gymnosperm Gnetum (Gnetales)-clock calibration when outgroup relationships are uncertain. Syst. Biol. 55, 610-622. doi: 10.1080/ 10635150600812619

Wu, C. S., Lai, Y. T., Lin, C. P., Wang, Y. N., and Chaw, S. M. (2009). Evolution of reduced and compact chloroplast genomes (cpDNAs) in gnetophytes: selection toward a lower-cost strategy. Molec. Phylogen. Evol. 52, 115-124. doi: 10.1016/j. ympev.2008.12.026

Wu, C. S., Wang, Y. N., Liu, S. M., and Chaw, S. M. (2007). Chloroplast Genome (cpDNA) of Cycas taitungensis and $56 \mathrm{cp}$ protein-coding genes of Gnetum parvifolium: insights into cpDNA evolution and phylogeny of extant seed plants. Mol. Biol. Evol. 24, 1366-1379. doi: 10.1093/molbev/ msm059

Yamori, W., Shikanai, T., and Makino, A. (2015). Photosystem I cyclic electron flow via chloroplast NADH dehydrogenase-like complex performs a physiological role for photosynthesis at low light. Sci. Rep. 5:13908. doi: 10.1038/srep13908

Yang, Y., Lin, L., and Ferguson, D. K. (2015). Parallel evolution of leaf morphology in gnetophytes. Org. Divers. Evol. 15, 651-662. doi: 10.1007/s13127-015-0226-6

Yin, X. D., Van der Putten, P. E. L., Driever, S. M., and Struik, P. C. (2016). Temperature response of bundle-sheath conductance in maize leaves. J. Exp. Bot. 67, 2699-2714. doi: 10.1093/jxb/erw104

Yuan, C. M., Wu, T., Geng, Y. F., Chai, Y., and Hao, J. B. (2016). Phenotypic plasticity of lianas in response to altered light environment. Ecol. Res. 31, 375-384. doi: 10.1007/s11284-016-1343-1

Zachos, J., Pagani, M., Sloan, L., Thomas, E., and Billups, K. (2001). Trends, rhythms, and aberrations in global climate 65 Ma to present. Science 292, 686-693. doi: 10.1126/science. 1059412

Zhang, C. J., Guo, J. Q., Chen, G. X., and Xie, H. C. (2005). Effects of high temperature and/or drought on growth and secondary metabolites in Ginkgo biloba leaves. J. Ecol. Rural Environ. 21, 11-15.

Zhong, B., Yonezawa, T., Zhong, Y., and Hasegawa, M. (2010). The position of gnetales among seed plants: overcoming pitfalls of chloroplast phylogenomics. Mol. Biol. Evol. 27, 2855-2863. doi: 10.1093/molbev/ msq170

Zwieniecki, M. A., and Boyce, C. K. (2014a). Evolution of a unique anatomical precision in angiosperm leaf venation lifts constraints on vascular plant ecology. Proc. Biol. Sci. 281:20132829. doi: 10.1098/rspb.2013.2829

Zwieniecki, M. A., and Boyce, C. K. (2014b). The role of cellulose fibers in Gnetum gnemon leaf hydraulics. Int. J. Plant Sci. 175, 1054-1061. doi: 10.1086/678089

Conflict of Interest Statement: The authors declare that the research was conducted in the absence of any commercial or financial relationships that could be construed as a potential conflict of interest.

Copyright (c) 2019 Deng, Hou, Liu, Li, Bartish, Tian, Chen, Du, Jiang and Shi. This is an open-access article distributed under the terms of the Creative Commons Attribution License (CC BY). The use, distribution or reproduction in other forums is permitted, provided the original author(s) and the copyright owner(s) are credited and that the original publication in this journal is cited, in accordance with accepted academic practice. No use, distribution or reproduction is permitted which does not comply with these terms. 